\section{Immune dysregulation in myelodysplastic syndrome}

\author{
Chiharu Sugimori, Alan F. List, \\ Pearlie K. Epling-Burnette
}

Immunology Program and Malignant Hematology Division, H. Lee Moffitt Cancer Center \& Research Institute, Tampa, FL, USA

\section{Abstract}

Myelodysplastic syndrome (MDS) represents one of the most challenging health-related problems in the elderly. Characterized by dysplastic morphology in the bone marrow in association with ineffective hematopoiesis, pathophysiological causes of this disease are diverse including genetic abnormalities within myeloid progenitors, altered epigenetics, and changes in the bone marrow microenvironment. The concept that T-cell mediated autoimmunity contributes to bone marrow failure has been widely accepted due to hematologic improvement after immunosuppressive therapy (IST) in a subset of patients. Currently, IST for MDS primarily involves anti-thymocyte globulin (ATG)-based regimens in which responsiveness is strongly associated with younger (under 60 years) age at disease onset. In such cases, progressive cytopenia may occur as a consequence of expanded self-reactive $\mathrm{CD}^{+}$ cytotoxic T lymphocytes (CTLs) that suppress hematopoietic progenitors. Although most hematologists agree that IST can offer durable hematologic remission in younger patients with MDS, an international clinical study and a better understanding of the molecular mechanisms contributing to the expansion of selfreactive CTLs is crucial. In this review, data accumulated in the US, Europe, and Asia will be summarized to provide insight and direction for a multi-center international trial.

\section{Overview of myelodysplastic syndrome}

\section{Incidence}

Idiopathic MDS, as opposed to treatmentrelated MDS, occurs with higher incidence in older individuals in the Western world. ${ }^{1,2}$ In the United States, the incidence of MDS from 2001 to 2003 was recently established from population-based cancer registries from the National Cancer Institute's Surveillance, Epidemiology, and End Results (SEER) Program and North American Association of Central Cancer Registries (NAACCR) databases and showed that the overall incidence is 3.4 per 100,000 (4.5 in men and 2.7 in women). The median age at diagnosis was 76 years, with $86 \%$ of cases over 60 years of age. ${ }^{3,4}$ Among racial groups in the US, white individuals had the highest incidence rate $(3.5 / 100,000$ in Whites) followed by African Americans (3.0/100,000), native Americans $(1.3 / 100,000)$ and Asians and Pacific Islanders $(2.6 / 100,000){ }^{3,4}$ Compared to the median age in the US, the median age of patients with MDS in Asian and African countries is younger (50 and 60 years old, respectively). ${ }^{5-11}$

\section{Current classification systems}

To account for heterogeneity within this disease, in the past few decades the MDS classification system was evolved. In 1982, the French-American-British (FAB) classification system was established, ${ }^{12}$ which was later refined to the World Health Organization (WHO) subtyping. ${ }^{13,14}$ And recently, the WHO classification was revised as the following groups: (1) refractory cytopenia with unilineage dysplasia (RCUD) that includes refractory anemia (RA), refractory neutropenia (RN), and refractory thrombocytopenia (RT); (2) refractory anemia with ringed sideroblasts (RARS); (3) refractory anemia with multilineage dysplasia (RCMD); (4) refractory anemia with excess blasts-1 (RAEB-1); (5) refractory anemia with excess blasts-2 (RAEB-2); (6) myelodysplastic syndrome, unclassified (MDS$\mathrm{U})$; (7) MDS associated with isolated $\operatorname{del}(5 \mathrm{q})$; and (8) refractory cytopenia of childhood (RCC) as a group of provisional entities. Major points of the modification are the following: (1) patients who lack convincing morphological dysplasia but have specific MDS-related cytogenetic abnormalities have presumptive evidence of MDS; (2) refractory neutropenia and thrombocytopenia are added, along with refractory anemia, to the category of RCUD; (3) patients with dysplasia and $<5 \%$ bone marrow (BM) blasts but $\geq 2 \%$ in the peripheral blood (PB) are classified RAEB1, and (4) a provisional entity, Refractory Cytopenia of Childhood (RCC) has been added; distinguishing RCC from aplastic anemia (AA) can be difficult.

The International Prognostic Scoring System (IPSS) was introduced as a universal risk stratification system for treatment decision making. ${ }^{1}$ IPSS considers the percentage of marrow blasts, the number of cytopenias, and bone marrow cytogenetics to predict survival and progression to AML. Patients with untreated MDS are categorized into four IPSS prognostic risk groups; low, intermediate-1 (Int-1), intermediate-2 (Int-2), and high-risk with median survival estimates of 5.7, 3.5, 1.2, and 0.4 years, respectively. The risk of AML evolution of $25 \%$ of patients was determined to
Correspondence: Pearlie K. Epling-Burnette, $\mathrm{H}$. Lee Moffitt Cancer Center \& Research Institute, MRC 4 East, 12902 Magnolia Dr, Tampa, FL 33612, USA. E-mail: pearlie.burnette@moffitt.org

Key words: myelodysplastic syndrome, autoimmunity, T lymphocytes, treatment.

Received for publication: 13 February 2009. Accepted for publication: 9 0ctober 2009.

This work is licensed under a Creative Commons Attribution 3.0 License (by-nc 3.0).

(C) Copyright C. Sugimori et al., 2010

Licensee PAGEPress, Italy

Hematology Reports 2010; 2:el

doi:10.4081/hr.2010.e

be 9.4 (low-risk), 3.3 (Int-1), 1.1 (Int-2), and 0.2 (high-risk) years, respectively.

The IPSS system was designed to be applied only at diagnosis in patients with de novo MDS and may not be suitable for serial assessment of patients whose disease evolves over time. Recently, the WHO classification-based prognostic scoring system (WPSS) was proposed to estimate survival and risk of AML transformation at multiple time points during the natural course of MDS. The WPSS score integrates the three most important prognostic factors in MDS patients classified according to WHO criteria: karyotype, WHO subgroup, and requirement for RBC transfusion as an indicator of symptomatic anemia. In contrast with the four risk groups identified by the IPSS, the WPSS stratifies MDS patients into five different risk categories: very low (score $=0$ ), low (1), intermediate (2), high (3-4), or very high (5-6). Significant differences can be seen among the five groups in overall survival $(\mathrm{P}<0.0001)$ and risk of AML transformation $(\mathrm{P}<0.0001)$. In an independent cohort of patients with MDS, median survival ranged from 140 months for patients with a score of 0 to ten months for those with a score of 5 or more. The most significant improvement in prognostic stratification compared with IPSS is observed in patients without excess blasts, primarily due to the strong impact of the number of dysplastic lineages and transfusion dependency.

Kantarjian et al. also proposed a new risk model in MDS that accounts for events not considered in the original IPSS. They analyzed 1,915 patients with MDS including secondary MDS and CMML. Only 507 patients (26\%) could be classified by the IPSS. ${ }^{15}$ A multivariate survival analysis identified a myelodysplastic syndrome risk score (Table 1). Four prognostic risk groups are proposed for the new risk model: (1) low-risk (score 0-4: 16\% of patients), in which patients have an estimated median survival of 54 months and a 3 -year survival rate of $63 \%$; (2) intermediate-1 risk (score $5-6 ; 24 \%$ of patients), 
in which patients have an estimated median survival of 25 months and a 3-year survival rate of $34 \%$; (3) intermediate-2 risk (score 7-8; $24 \%$ of patients), in which patients have an estimated median survival of 14 months and a 3-year survival rate of $16 \%$; and (4) high-risk (score $\geq 9 ; 36 \%$ of patients), in which patients have an estimated median survival of six months and a 3 -year survival rate of $4 \%$. The proposed model was validated in the separate test group and proved to be applicable at any time during the course of disease.

\section{Immunological pathophysiology}

\section{Overview}

Various pathological disturbances have been linked to the etiology of MDS including genes that are involved in cell cycle control, DNA repair, gene transcription, telomere length and other chromosome abnormalities, mitotic checkpoints, cell growth, apoptosis, and cell differentiation and maturation. ${ }^{16-21}$ In response to this pleiotropic biology, several therapeutic options have been developed in recent years including azacitidine, ${ }^{22}$ decitabine, ${ }^{23,24}$ and lenalidomide..$^{25-27}$ Information from the treatment of patients with these newer agents has influenced the opinion of investigators about the underlying pathogenesis of MDS.

\section{Dysregulation of immunity in tri- somy 8 myelodysplastic syndrome}

T-cell immune dysregulation is definitely associated with bone marrow failure in AA and large granular lymphocyte leukemia (LGLL), which share several clinical features with MDS. Historically, IST in MDS has been applied in cases with bone marrow hypocellularity; a clinical feature that is commonly associated with AA and observed in approximately 15\% of MDS cases. $^{28}$ Numerous abnormalities in immune function appear to contribute to impaired hematopoiesis including elevated plasma levels of several cytokines such as tumor necrosis factor-alpha (TNF- $\alpha)^{29,30}$ and interferon-gamma (IFN- $\gamma),{ }^{31}$ which are well-known contributors to AA pathogenesis. Many investigators have now confirmed that cytopenias are corrected by Tcell depleting immunotherapy in some MDS patients. ${ }^{32-35}$ From data in vitro and in vivo, the current consensus is that a few autologous $\mathrm{T}$ cells directly suppress erythroid (CFU-E) and granulocytic (CFU-GM) progenitor cell differentiation. ${ }^{36}$

A hallmark of T-cell dominant autoimmunity is the expansion of T-cell clones with restricted diversity that possess a limited T-cell receptor (TCR)-V $\beta$ repertoire. Limitation in TCR-V $\beta$ complementary-determining region 3 (CDR3)

Table 1. Simplified myelodysplastic syndrome risk score (0-15 Points).

\begin{tabular}{|c|c|c|}
\hline Prognostic Factor & Coefficient & Points \\
\hline $\begin{array}{l}\text { Performance status } \\
\geq 2\end{array}$ & 0,267 & 2 \\
\hline $\begin{array}{l}\text { Age, } y \\
\quad 60-64 \\
\geq 65\end{array}$ & $\begin{array}{l}0.179 \\
0.336\end{array}$ & $\begin{array}{l}1 \\
2\end{array}$ \\
\hline $\begin{array}{l}\text { Platelets, x109/L } \\
\quad<30 \\
30-49 \\
50-199\end{array}$ & $\begin{array}{l}0.418 \\
0.270 \\
0.184\end{array}$ & $\begin{array}{l}3 \\
2 \\
1\end{array}$ \\
\hline Hemoblobin <12 g/dL & 0.274 & 2 \\
\hline $\begin{array}{l}\text { Bone marrow blasts, } \% \\
5-10 \\
11-29\end{array}$ & $\begin{array}{l}0.222 \\
0.260\end{array}$ & $\begin{array}{l}1 \\
2\end{array}$ \\
\hline $\mathrm{WBC}>20 \times 10^{9} / \mathrm{L}$ & 0.258 & 2 \\
\hline $\begin{array}{l}\text { Karyotype: Chromosome } 7 \text { abnormality } \\
\text { or complex } \geq 3 \text { abnormalities }\end{array}$ & 0.479 & 3 \\
\hline Prior transfusion, yes & 0.107 & 1 \\
\hline
\end{tabular}

From Kantariian 15

diversity and clonal expansion of T cells in association with bone marrow suppression suggests that escape from peripheral tolerance and recognition of self-antigens may contribute to suppressive hematopoiesis. Peripheral tolerance may be averted by chromosomal aberrations, or other disease-specific changes that occur in the microenvironment. While the mechanisms that underlie the generation of Tcell clonal expansion remains elusive, EplingBurnette et al. showed that clonal T-cell expansion occurs in $50 \%$ of MDS patients compared to $5 \%$ in healthy individuals of a similar age range. Importantly, T-cell expansion was not restricted to specific IPSS, WHO subtypes, age, transfusion history, or karyotypes ${ }^{37}$ implying that T-cell expansion occurs commonly among all MDS prognostic subgroups. Sloand et al. has confirmed the identity of one antigen that drives abnormal T-cell clonal expansion that contributes to impaired hematopoiesis in patients with a trisomy 8 cytogenetic abnormality. ${ }^{38}$ This abnormality is seen in both MDS and AA and is associated with favorable prognosis. Indicative of underlying immune pathology, patients with trisomy 8 display an increased frequency of response to IST compared to patients with other chromosomal abnormalities. ${ }^{38}$ Clonally expanded $\mathrm{CD}^{+}$cells with reduced TCR-V $\beta$ repertoire diversity and direct cytotoxicity of autologous trisomy 8 hematopoietic progenitors was observed in vitro. ${ }^{39} \mathrm{CD} 8+$ T-cell self-reactivity was not observed in MDS patients with $5 \mathrm{q}$ - and monosomy 7 chromosomal abnormalities. ${ }^{39}$ Bone marrow progenitors with a trisomy 8 abnormality were more sensitive to Fas-mediated apoptosis and more likely to express activated apoptotic markers such as caspases. ${ }^{40}$ In addition, a small number of trisomy 8 cells were present in bone marrow by fluorescence in situ hybridization (FISH) long before cytogenetic conversion by standard metaphase karyotyping, suggesting that trisomy 8 aneuploidy may be an early event in MDS. It was hypothesized that the CTL response was initially triggered by abnormal stem cells but the bone marrow failure was subsequently mediated by a 'bystander' CTL response against healthy hematopoietic cells. The Wilms' tumor-1 (WT1) protein, which is localized on chromosome 8 , and thus overexpressed in MDS patients with trisomy 8, represents a well-defined target of self-reactive CTLs in IST responsive patients. ${ }^{41} \mathrm{~T}$ cells may undergo TCR-dependent activation in response to the overproduction of the WT1 antigen, differentiate into effector and memory cells that elicit a WT1-specific CTL response, and as a consequence lead to bone marrow failure through the destruction of both trisomy 8 and normal hematopoietic progenitors (HPCs). Long-term survival of WT1-specific T cells has previously been linked to the expression of c-myc, CD1, and survivin (an inhibitor of apoptosis). ${ }^{38,42}$

While the linkage between immune-mediated pathogenesis and trisomy 8 is mechanistically established, this chromosomal abnormality occurs in only $5-10 \%$ of MDS patients and more often in those that evolve from AA. Response to IST is clearly not restricted to this limited subpopulation of MDS patients suggesting that the mechanism of immune pathogenesis in patients without trisomy 8 must be explored further. The role of aberrant T-cell homeostasis and the relationship between skewed TCR-V $\beta$ repertoires in patients without a trisomy 8 is yet to be defined. In summary, distinguishing features of trisomy 8 positive bone marrow cells may represent a distinct 
pathophysiological entity associated with the direct stimulation of $\mathrm{CD} 8+\mathrm{T}$ cells that may receive benefit from IST (Figure 1).

\section{Search for predictive biomarkers of immune pathophysiology}

Since the mechanisms contributing to immune pathophysiology and patient selection criteria for IST remain elusive in patients without trisomy 8 , a search for predictive biomarkers is critically needed. Classic paroxysmal nocturnal hemoglobinuria $(\mathrm{PNH})$ is an acquired disease characterized by intravascular hemolysis that results from the clonal expansion of $P I G-A$ mutant hematopoietic stem cells (HSCs) producing blood cells deficient in glycosylphosphatidylinositol-anchored proteins (GPI-AP), such as CD55 (decay accelerating factor, DAF) and CD59 (membrane inhibitor of reactive lysis, MIRL). Such GPI-AP deficient (paroxysmal nocturnal hemoglobinuria (PNH) - type) cells are often detectable in the peripheral blood of patients with bone marrow failure syndromes including AA and RA as defined by the FAB group. ${ }^{43-45}$ How PNH-type cells arise and increase in patients with $\mathrm{BM}$ failure remains obscure. $P I G$-A mutation itself does not confer a proliferative advantage to HSCs. The most widely accepted mechanism for clonal expansion of PNH-type cells in patients with BM failure is the "escape hypothesis", which states that the relative number of PIG-A mutant HSCs increases by avoiding immunological attacks by $\mathrm{T}$ cells or $\mathrm{NK}$ cells. ${ }^{46,47}$ A murine study demonstrated that GPI-AP-deficient hematopoietic cells can evade a T-cell attack due to either the absence of the target peptide recognized by GPI-AP specific T cells, or the absence of accessory GPI-AP molecules, which are required for HSCs to be attacked by cytotoxic T cells. ${ }^{48}$ In MDS patients, the expansion of PNH-type cells have been reported in about $20 \%$ of the patients with lower-risk MDS and that phenomenon has been linked in some studies to IST responsiveness. ${ }^{43,44}$ The assay for PNH detection has not been standardized across institutions in the US and differs from that of Europe and Asia making the association between presence of PNH-type cells and response to IST difficult to interpret. ${ }^{49}$ Standardization of the assay around the world will likely improve the accuracy of this measure as a reliable biomarker of disease.

Recently, Zou et al. analyzed the age-adjusted CD4/CD8 ratio in 54 MDS patients compared to 37 healthy controls which revealed that inadequate $\mathrm{CD} 4^{+}$rather than expansion of $\mathrm{CD}^{+} \mathrm{T}$ cells was associated with a lower ratio in a group that included both lower and higher risk MDS patients defined by the International Prognostic Scoring System (IPSS). ${ }^{50}$ Inversion of the CD4/CD8 ratio was strongly associated with response to therapy $(\mathrm{P}<0.001)$. The loss

\section{Possible Mechanisms of Autoimmunity in MDS}

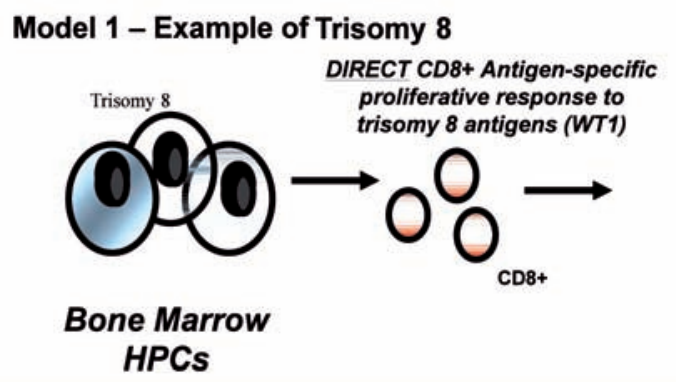

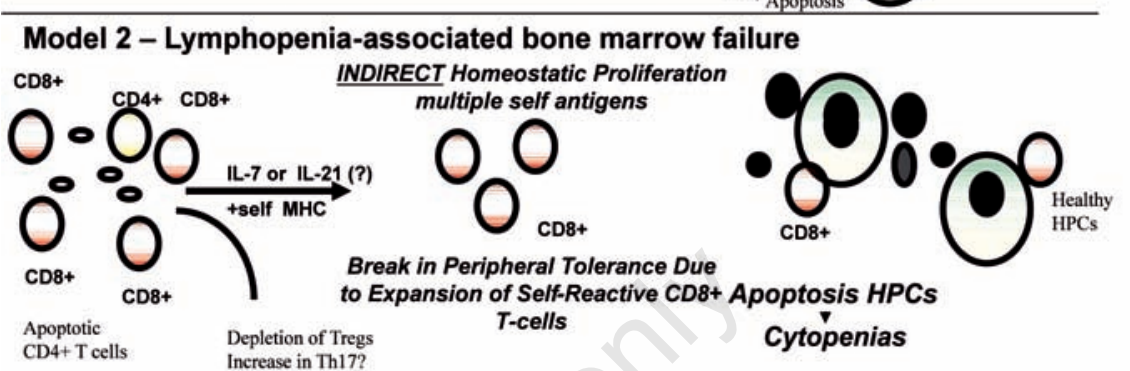

Figure 1. Molecular model of T-cell pathogenesis in MDS. Described in this review are the supporting data that link T-cell abnormalities to multiple abnormal events that include apoptotic response and the presence of inflammation in the bone marrow microenvironment. The mechanism controlling the expansion of self-reactive $\mathrm{CD8}^{+} \mathrm{T}$-cells appears to be two fold described by two models (DIRECT and INDIRECT); 1) there may be direct activation of $\mathrm{CD8}^{+} \mathrm{T}$ cells in response to abnormally expressed bone marrow antigens as exemplified by patients with trisomy 8 , and 2) there may be expansion of destructive CD8 T cells due to homeostatic cytokines of the IL-2R $\beta \gamma$ common cytokines which include IL7, IL-2, IL-15, and IL-21. From previous results, lymphopenia-associated autoimmunity has been linked to antigen-specific $\mathrm{CD8}^{+} \mathrm{T}$ cells with variable self- antigen reactivity. Survival advantage and clonal expansion dominates from $\mathrm{CD8}^{+}$self-reactive $\mathrm{T}$ cells that respond to antigen in the context of self-MHC class I bypassing peripheral tolerance mechanisms. Results suggest that self-reactive $\mathrm{CD8}^{+} \mathrm{T}$-cells are involved in the suppression of bone marrow progenitors through direct cytotoxicity of the MDS clones such as trisomy $8^{+}$HPCs or the release of cytokines such as TNF $\alpha$ and IFN $\gamma$. There is also evidence that depletion of $\mathrm{CD}^{+}$regulatory $\mathrm{T}$ cells (Tregs) and accumulation of IL-17-secreting $\mathrm{CD}^{+} \mathrm{T}$ cells (Th17) may be imbalanced. Evidence supports the role of these T-cell abnormalities in cytopenias and increased apoptosis observed in lower-risk MDS. HPC=Hematopoietic Progenitor Cells, WT1=Wilms' tumor 1 antigen.

of CD4-cells was inversely correlated to the proliferative T-cell index before treatment in IST-responsive patients suggesting that proliferation and accelerated CD4+ T-cell turnover may be important in disease pathogenesis. In many autoimmune diseases, there is a correlation between the loss of CD4 $4^{+} \mathrm{T}$ cells and the expansion of autoreactive CD8 ${ }^{+} \mathrm{T}$ cells. ${ }^{51}$ This abnormality supersedes the simple loss of $\mathrm{CD}^{+}{ }^{+}$regulatory $\mathrm{T}$ cells (Tregs) from the peripheral or tissue compartment. Reduction in CD4+ T cells may initiate a cytokine-dependent pathway known as "homeostatic proliferation" in which the interleukin (IL)-2R $\gamma$ common cytokines such as IL-2, IL-7, IL-15 and/or IL-21 non-specifically expand antigen-specific and self-reactive $\mathrm{T}$ cells leading to an increased risk for evasion of peripheral tolerance mechanisms leading to autoimmunity. ${ }^{52}$ Results by Zou et al. are the first to demonstrate involvement of $\mathrm{CD}^{+} \mathrm{T}$ cells and response to IST. Since the loss of CD4+ T cells is strongly associated with impaired T-cell homeostasis and accumulation of self-reactive $\mathrm{CD}^{+} \mathrm{T}$ cells contributes to autoimmunity in many models of human disease, this mechanism may explain immune pathogenesis from a global perspective. The highest homeostatic proliferative index is afforded to $\mathrm{T}$ cells with the highest affinity to self-antigens, explaining not only trisomy 8 autoimmunity, but also autoimmune pathogenesis in other settings. A discovery of T-cell receptor (TCR) antigen reactivity in patients with aggressive homeostatic proliferation, without trisomy 8 , is needed. Kordasti et al. recently showed that the numbers of $\mathrm{CD}^{+} \mathrm{CD}^{+}$IL-17 producing T cells (Th17) were markedly increased and CD4 ${ }^{+}$ $\mathrm{CD}^{2} 5^{\text {high }} \mathrm{FoxP}^{+}$regulatory $\mathrm{T}$ cells (Tregs) inversely decreased in lower risk MDS compared with higher risk MDS. ${ }^{53}$ Tregs from MDS patients suppressed IFN $-\gamma$ secretion by effector 
CD4+ T cells but had no effect on IL-17 production. In addition, the serum levels of IL-7, IL12 , RANTES and IFN- $\gamma$ are significantly elevated in lower risk MDS, while inhibitory factors, such as IL-10 and soluble IL-2 receptor, are significantly higher in high-risk disease. They concluded that the unfavorable Th17:Tregs ratio in low-risk MDS may explain the higher risk of autoimmunity and the improved response to immune suppression in patients with low-risk MDS compared to those with highrisk disease. ${ }^{53}$ In general, more work should be performed to determine the precise relationship between $\mathrm{CD} 4{ }^{+} \mathrm{T}$ cells, HLA DR15, and homeostatic turnover as an alternative mechanism of autoimmunity in MDS (Figure 1).

\section{Therapy}

\section{Response criteria}

In line with changes in the various classification systems, therapeutic response standards have also evolved. In 2000, the International Working Group (IWG) recom- mended specific criteria for response that defined four treatment goals including: (1) treatment that alters the natural history of the disease; (2) cytogenetic response; (3) hematologic improvement (HI); and (4) quality of life (QOL). ${ }^{54}$ The HI responses are particularly relevant in patients treated with IST since patients generally have lower risk disease, possess fewer bone marrow blasts, and suffer from long-standing cytopenia. The IWG criteria for HI define specific response to cytopenia in the three hematopoietic lineages; erythroid (HIE), platelet (HI-P), and neutrophils (HI-N). In 2006, the IWG proposed modifications to the response for altering natural history of MDS and hematologic improvement. These are summarized in Table $2 .{ }^{55}$

\section{ATG based regimens}

The goals of MDS therapy are to prolong survival, delay or prevent AML progression, and to improve QOL. Although allogeneic hematopoietic stem cell transplantation (HSCT) is the only curative treatment in MDS, eligibility for HSCT is limited due to the need for an HLAmatched donor and the procedure-related co- morbidities, which is particularly important in this older patient population. ${ }^{56}$ With the success of ATG in AA, there have been several studies of not only ATG but other ATG-combination therapies in MDS. ${ }^{57-59}$

ATG is a mixture of purified polyclonal $\operatorname{IgG}$ from the sera of rabbits (rATG, Thymoglobulin, Genzyme, Cambridge, MA) or horses (eATG) immunized with human thymocytes (Lymphoglobulin, and Atgam) or the Jurkat cell line (ATG Fresenius, Fresenius SE, Bad Homburg, Germany). ${ }^{60}$ ATG has diverse effects on the immune system including; (1) T-cell depletion in blood and peripheral lymphoid tissues through complement-dependent lysis and apoptosis; ${ }^{61}(2)$ modulation of key cell surface molecules that mediate leukocyte/epithelium interactions, ${ }^{62}(3)$ induction of apoptosis in Bcell lineages; ${ }^{63}$ (4) interference with dendritic cell functional properties; ${ }^{64}$ (5) induction of regulatory $\mathrm{T}^{65}$ and natural killer T cells, ${ }^{66}$ (6) direct effect on hematopoietic progenitor cell colony formation from primitive hematopoietic cells; ${ }^{67}$ and (7) possibly, elimination of the FasFas-L interactions. ${ }^{68}$ Each product has shown differential effects on the immune microenvironment and homeostasis. Table 3 summa-

Table 2. Proposed modified International Working Group response criteria.

$\begin{array}{ll}\text { Categony } & \text { For altering natural history of myelodysplastic syndrome } \\ \text { Response Criteria (responses must last at least } 4 \text { wk) }\end{array}$

Complete remission

Bone marrow: $\leq 5 \%$ myeloblasts with normal maturation of all cell lines

Persistent dysplasia will be noted

Peripheral blood

$\mathrm{Hgb} \geq 11 \mathrm{~g} / \mathrm{dL}$

Platelets $\geq 100 \times 10^{9} / \mathrm{L}$

Neutrophils $\geq 1.0 \times 10^{6} / \mathrm{L}$

Blasts 0\%

$\begin{array}{ll}\text { Partial remission } & \text { All CR criteria if abnormal before treatment expect: one marrow blasts decreased by } \geq 50 \% \\ & \text { over pre-treatment but still }>5 \% \\ \text { Cellurarity and morphology not relevant }\end{array}$

Marrow CR Bone marrow: $\leq 5 \%$ myeloblasts and decrease by $\geq 50 \%$ over treatment

Peripheral blood: if HI responses, they will be noted in addition to marrow CR

Stable disease

Failure to achieve at least PR, but no evidence of progression for $>8$ wks

$\begin{array}{ll}\text { Hematologic improvement } & \text { For hematologic improvement } \\ \text { Response Criteria (responses must last at least } 8 \text { wk) }\end{array}$

Erythroid response

(pretreatment, $<11 \mathrm{~g} / \mathrm{dL}$ )
Hgb increase by $\geq 1.5 \mathrm{~g} / \mathrm{dL}$

Relevant reduction of units of RBC transfusions by an absolute number of at least $4 \mathrm{RBC}$ transfusions/8 wk compared with the pre-treatment transfusion number in the previous $8 \mathrm{wk}$. Only RBC transfusions given for a $\mathrm{Hgb}$ of $\leq 9.0 \mathrm{~g} / \mathrm{dL}$

pre-treatment will count in the $\mathrm{RBC}$ transfusion response evaluation

Platelet response

(pre-treatment, $<100 \times 10^{9} / \mathrm{L}$ )

Neutrophil response

(pretreatment, $<1.0 \times 10 \% / \mathrm{L}$ )

Progression or relapse after $\mathrm{HI}$
Absolute increase of $\geq 30 \times 10^{9} / \mathrm{L}$ for the patients starting with $>20 \times 10^{9} / \mathrm{L}$ platelets Increase from $<20 \times 10^{9} / \mathrm{L}$ to $>20 \times 10^{9} / \mathrm{L}$ and by at least $100 \%$

At least $100 \%$ increase and an absolute increase $>0.5 \times 10^{9} / \mathrm{L}$

At least one of the following:

At least $50 \%$ decrement from maximum response levels in granulocytes or platelets

Reduction in $\mathrm{Hgb}$ by $\geq 1.5 \mathrm{~g} / \mathrm{dL}$

Transfusion dependence

From Zou ${ }^{50}$ 
Table 3. Clinical trials of ATG based regimen.

\begin{tabular}{|c|c|c|c|c|c|c|c|}
\hline $\begin{array}{l}\text { Auther } \\
\text { (Published year) ref }\end{array}$ & Country & $\mathbf{N}$ & $\begin{array}{l}\text { Age } \\
\text { (Median) }\end{array}$ & Treatment & Formulation & $\begin{array}{l}\text { RA } \\
(\%)\end{array}$ & $\begin{array}{l}\text { HR } \\
(\%)\end{array}$ \\
\hline Molldrem $(2002)^{69}$ & US & 61 & 60 & eATG & Atgam & 61 & 34 \\
\hline Saunthararajah $(2002)^{70}$ & US & 72 & 59 & eATG and/or CsA & Atgam & 46 & 29 \\
\hline Yazji $(2003)^{71}$ & US & 31 & 59 & eATG and CsA & Atgam & 58 & 23 \\
\hline Steensma $(2003)^{72}$ & US & 8 & 69 & eATG & Atgam & 25 & 0 \\
\hline Stadler $(2004)^{73}$ & Germany & 35 & 63 & $\begin{array}{l}\text { eATG } \\
\text { rATG }\end{array}$ & $\begin{array}{l}\text { Lymphoglobulin } \\
\text { Thymoglobulin }\end{array}$ & $\begin{array}{l}60 \\
80\end{array}$ & $\begin{array}{l}40 \\
27\end{array}$ \\
\hline Broliden $(2006)^{74}$ & Sweden & 20 & 64 & rATG and CsA & ATG Pharmacia & 85 & 30 \\
\hline $\operatorname{Lim}(2007)^{75 \pi}$ & $\begin{array}{l}\text { UK, Germany, } \\
\text { and Italy }\end{array}$ & $\begin{array}{l}96 \text { (UK, 65: Germany, } \\
\text { 13: Italy, 18) }\end{array}$ & 56 & eATG & Lymphoglobulin & 84 & 42 \\
\hline Sloand (2008) ${ }^{\$ 76}$ & US & $\begin{array}{l}116 \text { (eATG and CsA, } \\
\text { 42: eATG, 74) }\end{array}$ & 60 & $\begin{array}{l}\text { eATG and CsA } \\
\text { eATG }\end{array}$ & Atgam & 67 & $\begin{array}{l}48 \\
24\end{array}$ \\
\hline
\end{tabular}

RA, refractory anemia; HR, hematological response; eATG, equine antithymocyte globulin; rATG, rabbit antithymocyte globulin; CsA, cyclosporine. ๆ Responses were defined by IWG ctiteria. §Responses were the same when the response classification of the IWG criteria was retrospectively applied.

rizes the results of clinical trials with ATGbased regimens in MDS.

The first pilot study investigating ATG in patients with MDS was conducted by investigators at the National Institute of Health (NIH) in $1997^{77}$ and the mature data (median followup: 30 months) with a larger sample size was reported in $2002 .{ }^{69}$ In this single-arm prospective study, 61 transfusion-dependent patients with MDS (with <20\% blasts) were treated with one cycle of eATG (Atgam) at $40 \mathrm{mg} / \mathrm{kg} / \mathrm{d}$ for four days. The response criteria were as follows; (1) independence from transfusion for a minimum of six weeks with a sustained increase in hemoglobin, or (2) stable hemoglobin within eight months of ATG treatment, as measured from the time the patient last received a transfusion until reinstitution of RBC transfusions. Within eight months of treatment, 21 of 61 patients (34\%) no longer required red blood cell transfusions. Independence from transfusion was maintained in 17 of the 21 responders (81\%) for a median of 36 months (range 3-72 months). Ten of 21 patients (47.5\%) with severe thrombocytopenia had sustained increase in platelet counts, and 6 of 11 patients (55\%) with severe neutropenia had sustained neutrophil counts of greater than $1 \times 10^{9}$ cells $/ \mathrm{L}$. The clinical characteristics associated with response included younger age (Odds ratio, $0.45, \mathrm{P}=0.005$ ) and lower platelet counts (median $68 \times 10^{9} / \mathrm{L}$ vs. $135 \times 10 \% / \mathrm{L}, \mathrm{P}=0.038$ ).

Saunthararajah et al. reported that human leukocyte antigen (HLA)-DR15 is overrepresented and is predictive of response to IST in the patients with MDS. ${ }^{70}$ It is well known that HLA-DR15 is overrepresented in patients with $\mathrm{AA}$ and $\mathrm{PNH} .{ }^{78-80}$ Sloand et al. recently confirmed these findings in 129 MDS patients who received equine antithymocyte globulin (eATG, Atgam, Pfizer, New York, NY) with or without cyclosporine (CsA, Novartis, Basel, Switzerland) at the National Heart Lung Blood

Table 4. Comparison of response to CsA studies.

\begin{tabular}{|c|c|c|c|c|c|}
\hline $\begin{array}{l}\text { Auther } \\
\text { (Published year) }\end{array}$ & Country & N & $\begin{array}{c}\text { Age } \\
\text { (median) }\end{array}$ & $\begin{array}{l}\text { RA } \\
(\%)\end{array}$ & $\begin{array}{l}\text { HR } \\
(\%)\end{array}$ \\
\hline Jonasova $(1998)^{83}$ & Czech & 17 & 53 & 94 & 82 \\
\hline Catalano $(2000)^{84}$ & Italy & 9 & 63 & 100 & 55 \\
\hline Atoyebi $(2002)^{85}$ & UK & 6 & 70 & 100 & 0 \\
\hline Shimamoto $(2003)^{86 \pi}$ & Japan & 50 & 55 & 96 & 60 \\
\hline Dixit $(2005)^{87}$ & India & 19 & 48 & 68 & 58 \\
\hline Chen $(2006)^{88}$ & China & 32 & 46 & 78 & 63 \\
\hline Ishikawa $(2007)^{89 \oplus}$ & Japan & 20 & 52 & 85 & 53 \\
\hline
\end{tabular}

IResponses were defined by IWG ctiteria.

Institute (NHLBI). ${ }^{76}$ Of 129 patients treated with IST, 39 (30\%) achieved a hematologic response with a median follow-up of three years (0.03-11.3 years). Factors associated with response to IST were age and HLA-DR15 expression with the strongest linkage observed in patients under 61 years of age.

Yazji et al. reported a durable response rate of $23 \%$ with at least hematologic improvement. ${ }^{76}$ In comparison to the initial NIH studies, a wider spectrum of MDS patients including RA/RARS subtypes constituted $54 \%$ of the cohort and only $35 \%$ had normal cytogenetics (vs. $54 \%$ in studies by Molldrem et al. ${ }^{68,77}$ ) Another study conducted by Steensma et al. was terminated early due to a lack of clinical efficacy. ${ }^{72}$ The early closure was restricted to a small sample size of 8 subjects. No hematologic response was observed in any study subject. Different factors might have contributed to this disappointing result. This cohort shared unfavorable characteristics: all with a $\mathrm{Hbg}$ below $9 \mathrm{~g} / \mathrm{dL}$ (in comparison to $10 \mathrm{~g} / \mathrm{dL}$ in all the other studies), older age (range 62-74 years), 6 of 8 patients had RAEB-1 and only 2 of 8 subjects had an RA subtype. Based on the IPSS, $63 \%$ were Int- 1 and $36 \%$ were Int- 2 . Four patients had complex cytogenetics and only 2 had a normal karyotype. Hence, this cohort did not represent the low-risk MDS population that was predicted to respond to IST based on $\mathrm{NIH}$ criteria. The small sample size (with $95 \%$ confidence interval of 0-37\%) could not statistically exclude the $35-45 \%$ hematologic response reported in the literature.

In a non-randomized, single-arm trial by Killick et al., ${ }^{81}$ the efficacy of eATG (lymphoglobulin) was studied in a multi-institutional trial. Valuable data with a median followup of 34 months was reported in $2007 .{ }^{75} \mathrm{~A}$ total of 96 patients from centers in the UK ( $n=65)$, Germany ( $n=13)$, and Italy $(n=18)$ were treated with one cycle of lymphoglobulin at $15 \mathrm{mg} / \mathrm{kg} / \mathrm{d}$ for five days. The International Working Group (IWG) response criteria were applied to evaluate response. In this study, a total of 40 patients (42\%) achieved a hematologic response, of which 30 patients (75\%) displayed a durable hematologic response lasting a median duration of 31.5 months (range 6-92 months). In a multivariate analysis, both low IPSS ( $\mathrm{P}=0.018)$ and bone marrow hypocellularity $(\mathrm{P}=0.012)$ were independent predictors of response to ATG. In addition, IPSS was the sole predictor of overall survival, with Int-2 and high-risk patients having a significantly poor- 
er survival outcome $(\mathrm{P}<0.01)$.

Stadler et al. compared the efficacy of eATG (lymphoglobulin, $15 \mathrm{mg} / \mathrm{kg} / \mathrm{d}$ for five days, $\mathrm{n}=20$ ) to $\mathrm{rATG}$ (thymoglobulin, $3.75 \mathrm{mg} / \mathrm{kg} / \mathrm{d}$ for five days, $n=15$ ), which is commonly used for the treatment of AA. There was no significant difference between the two ATG products with regard to either the clinically relevant responses or frequency of adverse effects. ${ }^{73}$

Broliden et al. reported the efficacy of ATG and CsA therapy in MDS patients,${ }^{74}$ since this combination therapy is well known to be more effective in the patients with AA. ${ }^{82}$ Twenty patients (17 RA, 3 RAEB) received treatment with rATG (ATG-Fresenius) plus CsA. The overall response rate was $30 \%(6 / 20) ; 3$ of the 6 responders had a complete response. The responses lasted 2-58 months, with 2 patients still being in complete remission at 42 and 58 months, respectively.

\section{CsA usage in MDS}

Table 4 summarizes previous clinical trials of CsA in MDS. ${ }^{83-89}$ CsA has a strong immunosuppressive effect mediated by inactivation of the protein phosphatase calcineurin, resulting in the inhibition of IL-2 gene activation. ${ }^{90}$ Inhibition of proliferative CTL expansion may be critical for autoimmunity in MDS. The first prospective trial with CsA was designed by Janasova et al..$^{83}$ Seventeen cytopenic patients with MDS were treated and a durable response was observed in $82 \%$. Of note, 16 out of the 17 subjects had the RA subtype but varying degrees of bone marrow cellularity. Most patients had a normal karyotype or a single cytogenetic abnormality of 5q-, which both showed positive association with response in this study although $5 \mathrm{q}$ - was not associated with response to ATG in the recent NHLBI study. ${ }^{76}$ The selection of cohorts with only favorable profiles might contribute to the surprisingly high response rate. Catalano et al. treated 9 patients with RA and also demonstrated a favorable response. ${ }^{84}$ In contrast, another study reported by Atoyebi et al. ${ }^{85}$ showed no substantial response to CsA but an unacceptable toxicity profile. An older median age of the treatment group (70 years) may have impacted the therapeutic response and likely increased the risk of CsA-related nephrotoxicity.

There have been several reports of immunosuppression use from Asian countries. A large multicenter study of Japanese MDS patients was reported by Shimamoto et $a l .{ }^{86}$ Fifty low-risk MDS patients were treated with $\mathrm{CsA}(6 \mathrm{mg} / \mathrm{kg} / \mathrm{d})$ with variable marrow cellularity. Of these patients, 30 patients (60\%) showed hematologic improvement. Comparison of the clinical characteristics in responders and non-responders demonstrated that patients with a favorable karyotype, 0 or
0.5 IPSS score, and HLA-DRB $1 * 1501$ were more responsive than patients with intermediate or poor risk karyotypes, 1.0 or 1.5 IPSS score, and other HLA types, respectively. There was no significant difference between response to immunosuppressive therapy and age, BM cellularity, BM blast percentage, or dose and blood concentration of CsA. Moreover, they found that bone marrow dysplastic features were present regardless of hematologic response. This group demonstrated a significant association between hematologic improvement and an inverted CD4/CD8 ratio and TCR-V $\beta$ and $-\gamma$ gene rearrangements as biological predictors of response. ${ }^{91}$ Although correlative studies were carried out in only a few patients $(n=4)$, these results corroborate the findings by Zou et al. using samples from patients at the NHLBI. ${ }^{50}$ Recently, Ishikawa et al. suggested the significance of the PNH clone in patients with lowrisk MDS in a prospective study. ${ }^{89}$ They treated 20 patients with MDS with $\mathrm{CsA}(4 \mathrm{mg} / \mathrm{kg} / \mathrm{d})$. Among 19 patients evaluated, 10 showed hematologic improvement, most of the toxicity associated with CsA usage was manageable, and no patient had progressed to AML at the latest follow-up (median 30 months). A short duration of illness, RA with minimal bone marrow dysplasia, and the presence of the PNH clone were all significantly associated with a platelet response. A minority of RA patients who did not possess such predictive variables achieved an isolated erythroid response.

\section{Summary}

MDS is the one of the most challenging problems in hematology. Although the current classification and prognostic schemes have improved over the past decade, these pathological classification-based schemes are ineffective to distinguish pathological diversity and therapeutic response. Importantly, substantial clinical benefit is observed with IST treatment in the US, Europe, and Asia. Response rates of ATG therapy ranged from $20-40 \%$ and CsA response ranged from $50-60 \%$ using IWG response criteria. ATG therapy, however, has not been used in Asia and few trials of CsA therapy have been performed in Western countries creating an uncertainty about whether there are specific pathobiological features of the disease in Asia that predispose patients to IST response or whether CsA therapy is superior to ATG therapy. For the most effective application of IST, definitive mechanisms of pathophysiology and biological predictors of response must be established. A large clinical trial that includes international centers and compares ATG to CsA will clarify the features associated with immune-mediated MDS. This study should include not only clinical response assessment but also correlative laboratory analyses of variables shown previously to predict for hematologic improvement such as Tcell clonality, T-cell homeostasis, HLA type, microarray expression profiling, and $\mathrm{PNH}$ analysis. To detect PNH-type cells, a sensitive assay must be applied to detect small expansions of these cells. In conclusion, the concept of autoimmunity in MDS patients is widely accepted but, clarification of the autoimmune mechanism contributing to bone marrow myelodysplasia and impaired hematopoiesis must be obtained. In the future, the focus should be on developing an international coordinated clinical trial to define geographical and therapeutic differences, newer approaches to immune modulation, and basic studies to understand the pathophysiological mechanisms.

\section{References}

1. Greenberg P, Cox C, LeBeau MM, et al. International scoring system for evaluating prognosis in myelodysplastic syndromes. Blood 1997;89:2079-88.

2. Estey E. Acute myeloid leukemia and myelodysplastic syndromes in older patients. J Clin Oncol 2007;25:1908-15.

3. Ma X, Does M, Raza A, Mayne ST. Myelodysplastic syndromes: incidence and survival in the United States. Cancer 2007;109:1536-42.

4. Rollison DE, Howlader N, Smith MT, et al. Epidemiology of myelodysplastic syndromes and chronic myeloproliferative disorders in the United States, 2001-2004, using data from the NAACCR and SEER programs. Blood 2008;112:45-52.

5. Chen B, Zhao WL, Jin J, et al. Clinical and cytogenetic features of 508 Chinese patients with myelodysplastic syndrome and comparison with those in Western countries. Leukemia 2005;19:767-75.

6. Lee JH, Shin YR, Lee JS, et al. Application of different prognostic scoring systems and comparison of the FAB and WHO classifications in Korean patients with myelodysplastic syndrome. Leukemia. 2003;17:305-13.

7. Toyama K, Ohyashiki K, Yoshida Y, et al. Clinical implications of chromosomal abnormalities in 401 patients with myelodysplastic syndromes: a multicentric study in Japan. Leukemia. 1993;7:499-508.

8. Intragumtornchai T, Prayoonwiwat W, Swasdikul D, et al. Myelodysplastic syndromes in Thailand: a retrospective pathologic and clinical analysis of 117 cases. 
Leuk Res 1998;22:453-60.

9. Paydas S, Kocak R. Younger age observation in myelodysplastic syndrome. Leuk Res 1996;20:367.

10. Chatterjee T, Dixit A, Mohapatra M, et al. Clinical, haematological and histomorphological profile of adult myelodysplastic syndrome. Study of 96 cases in a single institute. Eur J Haematol 2004;73:93-7.

11. Mukiibi JM, Paul B. Myelodysplastic syndromes (MDS) in Central Africans. Trop Geogr Med 1994;46:17-9.

12. Bennett JM, Catovsky D, Daniel MT, et al. Proposals for the classification of the myelodysplastic syndromes. Br J Haematol 1982;51:189-99.

13. Harris NL, Jaffe ES, Diebold J, et al. World Health Organization classification of neoplastic diseases of the hematopoietic and lymphoid tissues: report of the Clinical Advisory Committee meeting-Airlie House, Virginia, November 1997. J Clin Oncol 1999;17:3835-49.

14. Vardiman JW, Harris NL, Brunning RD. The World Health Organization (WHO) classification of the myeloid neoplasms. Blood 2002;100:2292-302.

15. Kantarjian H, O'Brien S, Ravandi F, et al. Proposal for a new risk model in myelodysplastic syndrome that accounts for events not considered in the original International Prognostic Scoring System. Cancer 2008;113:1351-61.

16. Pfeilstocker M, Karlic H, Nosslinger T, et al. Myelodysplastic syndromes, aging, and age: correlations, common mechanisms, and clinical implications. Leuk Lymphoma 2007;48:1900-9.

17. Rigolin GM, Porta MD, Bugli AM, et al. Flow cytometric detection of accelerated telomere shortening in myelodysplastic syndromes: correlations with aetiological and clinical-biological findings. Eur $\mathrm{J}$ Haematol 2004;73:351-8.

18. Ohyashiki K, Shay JW, Ohyashiki JH. Lack of mutations of the human telomerase RNA gene (hTERC) in myelodysplastic syndrome. Haematologica 2005;90:691.

19. Hopfer O, Komor M, Koehler IS, et al. DNA methylation profiling of myelodysplastic syndrome hematopoietic progenitor cells during in vitro lineage-specific differentiation. Exp Hematol 2007;35:712-23.

20. Sloand EM, Yong AS, Ramkissoon S, et al. Granulocyte colony-stimulating factor preferentially stimulates proliferation of monosomy 7 cells bearing the isoform IV receptor. Proc Natl Acad Sci USA 2006;103: 14483-8.

21. Zang DY, Goodwin RG, Loken MR, Bryant E, Deeg HJ. Expression of tumor necrosis factor-related apoptosis-inducing ligand, Apo2L, and its receptors in myelodysplastic syndrome: effects on in vitro hemopoiesis.
Blood 2001;98:3058-65.

22. Silverman LR, McKenzie DR, Peterson BL, et al. Further analysis of trials with azacitidine in patients with myelodysplastic syndrome: studies 8421,8921 , and 9221 by the Cancer and Leukemia Group B J Clin Oncol 2006;24:3895-903.

23. Issa JP, Garcia-Manero G, Giles FJ, et al. Phase 1 study of low-dose prolonged exposure schedules of the hypomethylating agent 5-aza-2'-deoxycytidine (decitabine) in hematopoietic malignancies. Blood 2004;103:1635-40.

24. Kantarjian H, Oki Y, Garcia-Manero G, et al. Results of a randomized study of 3 schedules of low-dose decitabine in higher-risk myelodysplastic syndrome and chronic myelomonocytic leukemia. Blood 2007;109:52-7.

25. List A, Kurtin S, Roe DJ, et al. Efficacy of lenalidomide in myelodysplastic syndromes. N Engl J Med 2005;352:549-57.

26. List A, Dewald G, Bennett J, et al. Lenalidomide in the myelodysplastic syndrome with chromosome $5 \mathrm{q}$ deletion. N Engl J Med 2006;355:1456-65.

27. Raza A, Reeves JA, Feldman EJ, et al. Phase 2 study of lenalidomide in transfusion-dependent, low-risk, and intermediate-1 risk myelodysplastic syndromes with karyotypes other than deletion $5 \mathrm{q}$. Blood 2008;111:86-93.

28. Young NS, Maciejewski J. The pathophysiology of acquired aplastic anemia. N Engl J Med 1997;336:1365-72.

29. Kitagawa M, Saito I, Kuwata T, et al. Overexpression of tumor necrosis factor (TNF)-alpha and interferon (IFN)-gamma by bone marrow cells from patients with myelodysplastic syndromes. Leukemia 1997;11:2049-54.

30. Molnar L, Berki T, Hussain A, Nemeth P, Losonczy $\mathrm{H}$. The role of TNF-alpha in myelodysplastic syndrome: immunoserologic and immunohistochemical studies. Orv Hetil 2000;141:1807-11.

31. Selleri C, Maciejewski JP, Catalano L, et al. Effects of cyclosporine on hematopoietic and immune functions in patients with hypoplastic myelodysplasia: in vitro and in vivo studies. Cancer 2002;95:1911-22.

32. Molldrem JJ, Jiang YZ, Stetler-Stevenson $\mathrm{M}$, et al. Haematological response of patients with myelodysplastic syndrome to antithymocyte globulin is associated with a loss of lymphocyte-mediated inhibition of CFU-GM and alterations in T-cell receptor Vbeta profiles. Br J Haematol 1998;102: 1314-22.

33. Kochenderfer JN, Kobayashi S, Wieder ED, et al. Loss of T-lymphocyte clonal dominance in patients with myelodysplastic syndrome responsive to immunosuppression. Blood 2002;100:3639-45.
34. Epperson DE, Nakamura R, Saunthararajah Y, et al. Oligoclonal T cell expansion in myelodysplastic syndrome: evidence for an autoimmune process. Leuk Res 2001;25:1075-83.

35. Kook H, Zeng W, Guibin C, et al. Increased cytotoxic T cells with effector phenotype in aplastic anemia and myelodysplasia. Exp Hematol 2001;29:1270-7.

36. Baumann I, Scheid C, Koref MS, et al. Autologous lymphocytes inhibit hemopoiesis in long-term culture in patients with myelodysplastic syndrome. Exp Hematol 2002;30:1405-11.

37. Epling-Burnette PK, Painter JS, Rollison DE, et al. Prevalence and clinical association of clonal T-cell expansions in myelodysplastic syndrome. Leukemia 2007;21:659-67.

38. Sloand EM, Rezvani K. The role of the immune system in myelodysplasia: implications for therapy. Semin Hematol. 2008;45:39-48.

39. Sloand EM, Mainwaring L, Fuhrer M, et al. Preferential suppression of trisomy $8 \mathrm{com}$ pared with normal hematopoietic cell growth by autologous lymphocytes in patients with trisomy 8 myelodysplastic syndrome. Blood 2005;106:841-51.

40. Sloand EM, Kim S, Fuhrer M, et al. Fasmediated apoptosis is important in regulating cell replication and death in trisomy 8 hematopoietic cells but not in cells with other cytogenetic abnormalities. Blood 2002;100:4427-32.

41. Chen G, Zeng W, Miyazato A, et al. Distinctive gene expression profiles of CD34 cells from patients with myelodysplastic syndrome characterized by specific chromosomal abnormalities. Blood 2004; 104:4210-8.

42. Sloand EM, Pfannes L, Chen G, et al. CD34 cells from patients with trisomy 8 myelodysplastic syndrome (MDS) express early apoptotic markers but avoid programmed cell death by up-regulation of antiapoptotic proteins. Blood 2007; 109:2399-405.

43. Dunn DE, Tanawattanacharoen P, Boccuni P, et al. Paroxysmal nocturnal hemoglobinuria cells in patients with bone marrow failure syndromes. Ann Intern Med 1999; 131:401-8.

44. Wang H, Chuhjo T, Yasue S, et al. Clinical significance of a minor population of paroxysmal nocturnal hemoglobinuriatype cells in bone marrow failure syndrome. Blood 2002;100:3897-902.

45. Sugimori C, Chuhjo T, Feng X, et al. Minor population of CD55-CD59- blood cells predicts response to immunosuppressive therapy and prognosis in patients with aplastic anemia. Blood 2006;107:1308-14.

46. Murakami Y, Kosaka H, Maeda Y, et al. 
Inefficient response of $\mathrm{T}$ lymphocytes to glycosylphosphatidylinositol anchor-negative cells: implications for paroxysmal nocturnal hemoglobinuria. Blood 2002;100: 4116-22.

47. Nagakura S, Ishihara S, Dunn DE, et al. Decreased susceptibility of leukemic cells with PIG-A mutation to natural killer cells in vitro. Blood 2002;100:1031-7.

48. Luzzatto L, Bessler M, Rotoli B. Somatic mutations in paroxysmal nocturnal hemoglobinuria: a blessing in disguise? Cell 1997;88:1-4.

49. Parker C, Omine M, Richards S, et al. Diagnosis and management of paroxysmal nocturnal hemoglobinuria. Blood 2005; 106:3699-709.

50. Zou JX, Rollison DE, Boulware D, et al. Altered naive and memory CD4+ T-cell homeostasis and immunosenescence characterize younger patients with myelodysplastic syndrome. Leukemia 2009.

51. Goronzy JJ, Weyand CM. Rheumatoid arthritis. Immunol Rev 2005;204:55-73.

52. Krupica T Jr., Fry TJ, Mackall CL. Autoimmunity during lymphopenia: a two-hit model. Clin Immunol 2006;120:121-8.

53. Kordasti SY, Afzali B, Lim Z, et al. IL-17producing CD4(+) T cells, pro-inflammatory cytokines and apoptosis are increased in low risk myelodysplastic syndrome. $\mathrm{Br} \mathrm{J}$ Haematol 2009;145:64-72.

54. Cheson BD, Bennett JM, Kantarjian H, et al. Report of an international working group to standardize response criteria for myelodysplastic syndromes. Blood 2000; 96:3671-4.

55. Cheson BD, Greenberg PL, Bennett JM, et al. Clinical application and proposal for modification of the International Working Group (IWG) response criteria in myelodysplasia. Blood 2006;108:419-25.

56. Luger S, Sacks N. Bone marrow transplantation for myelodysplastic syndrome--who? when? and which? Bone Marrow Transplant 2002;30:199-206.

57. Marsh J, Schrezenmeier H, Marin P, et al. Prospective randomized multicenter study comparing cyclosporin alone versus the combination of antithymocyte globulin and cyclosporin for treatment of patients with nonsevere aplastic anemia: a report from the European Blood and Marrow Transplant (EBMT) Severe Aplastic Anaemia Working Party. Blood 1999; 93:2191-5.

58. Bacigalupo A, Bruno B, Saracco P, et al. Antilymphocyte globulin, cyclosporine, prednisolone, and granulocyte colonystimulating factor for severe aplastic anemia: an update of the GITM0/EBMT study on 100 patients. European Group for Blood and Marrow Transplantation (EBMT)
Working Party on Severe Aplastic Anemia and the Gruppo Italiano Trapianti di Midollo Osseo (GITMO). Blood 2000; 95: 1931-4.

59. Young N, Griffith P, Brittain E, et al. A multicenter trial of antithymocyte globulin in aplastic anemia and related diseases. Blood 1988;72:1861-9.

60. Mohty M. Mechanisms of action of antithymocyte globulin: T-cell depletion and beyond. Leukemia 2007;21:1387-94.

61. Bonnefoy-Berard N, Vincent C, Revillard JP. Antibodies against functional leukocyte surface molecules in polyclonal antilymphocyte and antithymocyte globulins. Transplantation 1991;51:669-73.

62. Michallet MC, Preville X, Flacher M, et al. Functional antibodies to leukocyte adhesion molecules in antithymocyte globulins. Transplantation 2003;75:657-62.

63. Zand MS, Vo T, Huggins J, et al. Polyclonal rabbit antithymocyte globulin triggers Bcell and plasma cell apoptosis by multiple pathways. Transplantation 2005;79:150715.

64. Haidinger M, Geyeregger R, Poglitsch M, et al. Antithymocyte globulin impairs Tcell/antigen-presenting cell interaction: disruption of immunological synapse and conjugate formation. Transplantation 2007;84:117-21.

65. Lopez M, Clarkson MR, Albin M, et al. A novel mechanism of action for anti-thymocyte globulin: induction of CD4+CD25+ Foxp3+ regulatory $\mathrm{T}$ cells. J Am Soc Nephrol 2006;17:2844-53.

66. Lan F, Zeng D, Higuchi M, et al. Predominance of NK1.1+TCR alpha beta+ or DX5+TCR alpha beta+ T cells in mice conditioned with fractionated lymphoid irradiation protects against graft-versushost disease: "natural suppressor" cells. J Immunol 2001;167:2087-96.

67. Killick SB, Marsh JC, Gordon-Smith EC, Sorlin L, Gibson FM. Effects of antithymocyte globulin on bone marrow CD34+ cells in aplastic anaemia and myelodysplasia. Br J Haematol 2000;108:582-91.

68. Killick SB, Cox CV, Marsh JC, et al. Mechanisms of bone marrow progenitor cell apoptosis in aplastic anaemia and the effect of anti-thymocyte globulin: examination of the role of the Fas-Fas-L interaction. Br J Haematol 2000;111:1164-9.

69. Molldrem JJ, Leifer E, Bahceci E, et al. Antithymocyte globulin for treatment of the bone marrow failure associated with myelodysplastic syndromes. Ann Intern Med 2002;137:156-63.

70. Saunthararajah Y, Nakamura R, Nam JM, et al. HLA-DR15 (DR2) is overrepresented in myelodysplastic syndrome and aplastic anemia and predicts a response to immunosuppression in myelodysplastic syn- drome. Blood 2002;100:1570-4.

71. Yazji S, Giles FJ, Tsimberidou AM, et al. Antithymocyte globulin (ATG)-based therapy in patients with myelodysplastic syndromes. Leukemia 2003;17:2101-6.

72. Steensma DP, Dispenzieri A, Moore SB, et al. Antithymocyte globulin has limited efficacy and substantial toxicity in unselected anemic patients with myelodysplastic syndrome. Blood 2003;101:2156-8.

73. Stadler M, Germing U, Kliche KO, et al. A prospective, randomised, phase II study of horse antithymocyte globulin vs rabbit antithymocyte globulin as immune-modulating therapy in patients with low-risk myelodysplastic syndromes. Leukemia 2004;18:460-5.

74. Broliden PA, Dahl IM, Hast R, et al. Antithymocyte globulin and cyclosporine A as combination therapy for low-risk nonsideroblastic myelodysplastic syndromes. Haematologica 2006;91:667-70.

75. Lim ZY, Pearce L, Ho AY, et al. Delayed attainment of full donor chimaerism following alemtuzumab-based reducedintensity conditioning haematopoeitic stem cell transplantation for acute myeloid leukaemia and myelodysplastic syndromes is associated with improved outcomes. $\mathrm{Br}$ J Haematol 2007;138:517-26.

76. Sloand EM, Wu CO, Greenberg P, et al. Factors affecting response and survival in patients with myelodysplasia treated with immunosuppressive therapy. J Clin Oncol 2008;26:2505-11.

77. Molldrem JJ, Caples M, Mavroudis D, et al Antithymocyte globulin for patients with myelodysplastic syndrome. Br J Haematol 1997;99:699-705.

78. Kapustin SI, Popova TI, Lyschov AA, et al. HLA-DR2 Frequency increase in severe aplastic anemia patients is mainly attributed to the prevalence of DR15 subtype. Pathol Oncol Res 1997;3:106-8.

79. Nakao S, Takamatsu H, Chuhjo T, et al. Identification of a specific HLA class II haplotype strongly associated with susceptibility to cyclosporine-dependent aplastic anemia. Blood 1994;84:4257-61.

80. Maciejewski JP, Follmann D, Nakamura R, et al. Increased frequency of HLA-DR2 in patients with paroxysmal nocturnal hemoglobinuria and the $\mathrm{PNH} /$ aplastic anemia syndrome. Blood 2001;98:3513-9.

81. Killick SB, Mufti G, Cavenagh JD, et al. A pilot study of antithymocyte globulin (ATG) in the treatment of patients with 'low-risk' myelodysplasia. Br J Haematol 2003;120:679-84.

82. Frickhofen N, Heimpel H, Kaltwasser JP, Schrezenmeier H. Antithymocyte globulin with or without cyclosporin A: 11-year follow-up of a randomized trial comparing treatments of aplastic anemia. Blood 
2003;101:1236-42.

83. Jonasova A, Neuwirtova R, Cermak J, et al. Cyclosporin A therapy in hypoplastic MDS patients and certain refractory anaemias without hypoplastic bone marrow. $\mathrm{Br} \mathrm{J}$ Haematol 1998;100:304-9.

84. Catalano L, Selleri C, Califano C, et al. Prolonged response to cyclosporin-A in hypoplastic refractory anemia and correlation with in vitro studies. Haematologica 2000;85:133-8.

85. Atoyebi W, Bywater L, Rawlings L, et al. Treatment of myelodysplasia with oral cyclosporin. Clin Lab Haematol 2002;24: 211-4.
86. Shimamoto T, Tohyama K, Okamoto T, et al. Cyclosporin A therapy for patients with myelodysplastic syndrome: multicenter pilot studies in Japan. Leuk Res 2003; 27:783-8.

87. Dixit A, Chatterjee T, Mishra P, et al. Cyclosporin A in myelodysplastic syndrome: a preliminary report. Ann Hematol 2005;84:565-8.

88. Chen SC, Jiang B, Da WM, Gong M, Guan M. Curative effects of cyclosporin A therapy upon myelodysplastic syndrome. Zhonghua Yi Xue Za Zhi 2006;86:2711-5.

89. Ishikawa T, Tohyama K, Nakao S, et al. A prospective study of cyclosporine A treat- ment of patients with low-risk myelodysplastic syndrome: presence of CD55(-) CD59(-) blood cells predicts platelet response. Int J Hematol 2007;86:150-7.

90. Cai W, Hu L, Foulkes JG. Transcriptionmodulating drugs: mechanism and selectivity. Curr Opin Biotechnol 1996;7:608-15.

91. Shimamoto T, Iguchi T, Ando K, et al. Successful treatment with cyclosporin A for myelodysplastic syndrome with erythroid hypoplasia associated with T-cell receptor gene rearrangements. $\mathrm{Br} \mathrm{J}$ Haematol 2001;114:358-61. 